\title{
EXPERIMENTAL CHANGES IN RESOURCE STRUCTURE AND MALE DENSITY: SIZE-RELATED DIFFERENCES IN MATING SUCCESS AMONG MALE SCATOPHAGA STERCORARIA
}

\author{
Gerald Borgia ${ }^{1}$ \\ Museum of Zoology, University of Michigan, Ann Arbor, Michigan 48109
}

Received May 12, 1980. Revised August 6, 1981

The distribution of resources used by females often has important effects on patterns of male mating success. Correlations between the type and distribution of resources and types of mating systems were noted by Crook (1964, 1965). Orians and his associates (Verner, 1964; Verner and Wilson, 1966; Orians, 1969) developed the first models to describe the influence of resource distribution on female mating decisions. More recently these models have been reviewed (Bradbury and Vehrencamp, 1977; Emlen and Oring, 1977; Payne and Payne, 1977; Wittenburger, 1979) and developed in greater detail (Alexander, 1975; Altmann et al., 1977; Borgia, 1979). Increasingly it is recognized that patterns of matings in populations are key elements in social behavior in most species, yet there are few data to validate current hypotheses concerning the evolution of mating strategies in each sex. Available evidence is almost all comparative (but see Plesczynska, 1978), and although valuable, its correlative nature makes it especially subject to a variety of interpretations and often not suitable to separate competing hypotheses (see Altmann et al., 1977).

The mating system of the fly Scatophaga stercoraria (Diptera: Scatophagidae) has proven especially suited for experimental tests of hypotheses about mating strategies (Borgia, 1979). Males commonly aggregate on droppings or pats of cow dung that are used as oviposition sites by females. The number and location of suitable ovi-

\footnotetext{
${ }^{1}$ Present address: Department of Zoology, University of Maryland, College Park, Maryland 20742.
}

position sites vary diurnally and seasonally. Females who visit oviposition sites are captured by males who copulate with them and "guard" them until oviposition is complete (Hammer, 1941; Foster, 1961; Parker, 1970a, 1970b, 1970d). Parker $(1970 c)$ has shown that the last male to mate with a female fertilizes approximately $70 \%$ of her eggs; therefore male mating success provides a reasonable estimate of reproductive success. Individuals of both sexes, but especially males, are variable in size (males $5.2 \mathrm{~mm}-11.4 \mathrm{~mm}$; females $4.8 \mathrm{~mm}-9.3 \mathrm{~mm}$ ). Size differences among males appear to be important in (1) male exclusion of sexual competitors at low male densities; (2) male takeover or replacement of other males who are paired with females; and (3) male activity patterns and effectiveness in searching for mates (see Borgia, 1981).

The wide range in male size and high variation in availability of oviposition sites suggest that Scatophaga is useful for experimentally testing models of mating systems. Such experiments are valuable for two reasons. First, they allow study of how changes in resource availability affect patterns of male and female movement over the array of resources. Second, comparisons of the proportion of matings gained by males of different size classes indicate effects of resource structure on patterns of male mating success.

Because male Scatophaga capture females and females have only limited opportunities to choose mates, changes in resource structure may have effects on patterns of male mating success different from predictions from avian models, in which females have free choice of mates 
(see Borgia, 1979). Below I report the results of how experimental changes in male population density and resource availability influence male patterns of movement and mating success in Scatophaga.

\section{Methods}

Appraisal of size-specific reproductive success was made for two states of each of two variables: pat availability and male density. For each of the four treatment conditions I measured the size of amplexing males and of unpaired males on pats, and the distribution of males and pairs on pats. Measurements of male size were begun $45 \mathrm{~min}$ after the last pat was positioned (see below) and were continued until all pats had been surveyed. Surveys of male distribution on pats were carried out at 1-h intervals up to $3 \mathrm{~h}$ after the last pat was positioned.

Experiments were carried out in the fall of 1975: September (13th-28th) for low male density and late October (13th-29th) for high male density. Experiments with high and low levels of pat availability were run alternately as weather conditions permitted. Each treatment was repeated twice at low male density and three times at high male density. High pat availability involved 161-186 pats, each $18 \mathrm{~cm}$ in diameter, placed at regular intervals with a minimum of $1 \mathrm{~m}$ between pats on a grassy east-facing slope. In the low pat availability experiments, six pats, $18 \mathrm{~cm}$ in diameter, were placed $10 \mathrm{~m}$ apart on the same slope. Four large plastic cans with screen lids containing dung were placed in the vicinity of these pats, to enhance the long distance signal of dung to flies in adjacent pastures. The changes in pat numbers in these experiments were within limits commonly experienced by flies under normal conditions.

Special efforts were made to make pats of uniform attractiveness to flies, by rapidly placing pats of uniform size and shape in the pasture with a large spoon. Dung was collected in a dairy barn from at least six cows who were kept on a constant diet with water always available. The dung was stirred together and rapidly placed in

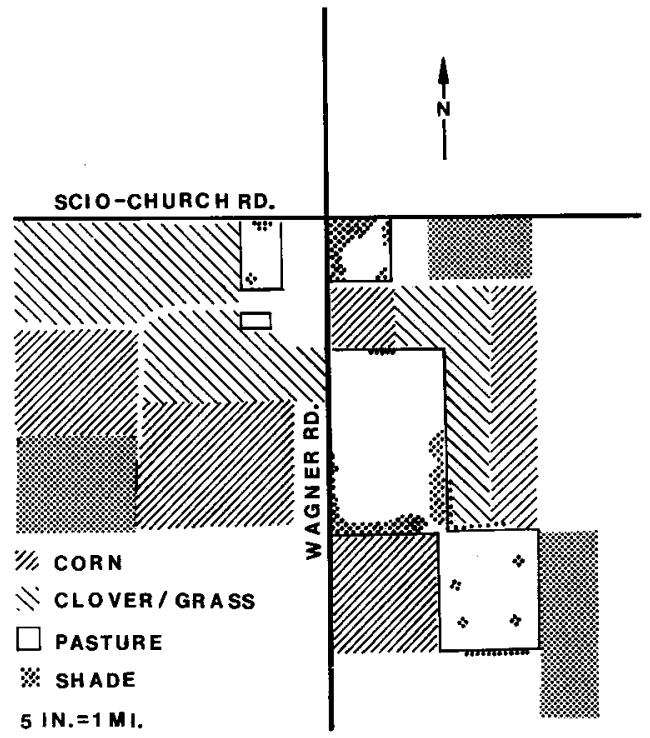

FIG. 1. Map of the farm where study site is located. The large pasture on the east side of Wagner Road is the site where experiments were carried out.

uniform pats to avoid time-dependent change in pat quality (Parker, 1970). All pats were laid out early, before flies colonized the pats.

Wind speed and direction strongly affect colonization of pats by flies. Flies generally fly upwind to locate dung pats (Parker, $1970 b, 1970 c$ ), so the likelihood that flies will utilize a particular pat is dependent on the location of fly roosts, the position of pats, and wind direction and speed. During this study, wind was from the prevailing direction WNW or adjacent points. Wind blew from this direction across a pasture and then a clover field where flies roosted overnight and during the warmest part of the day (see Fig. 1). At the beginning of experiments flies were downwind from the pats.

Flies were captured either in glass vials $(8.5 \mathrm{~mm} \times 2.2 \mathrm{~mm})$ placed over the fly or flies, or by means of large nets. Vials were used primarily for capturing mating or ovipositing pairs and a large net was used to take large samples of flies on and near the pats.

Wing length, measured by Helios needle point dial calipers, was used to estimate 
TABLE 1. Number of males per pat.

\begin{tabular}{|c|c|c|c|}
\hline & & \multicolumn{2}{|c|}{ Resource availability } \\
\hline & & High & Low \\
\hline \multirow[t]{2}{*}{ Male density } & High & $1.19 \pm 0.07$ & $27.6 \pm 5.74$ \\
\hline & Low & $0.95 \pm 0.04$ & $9.0 \pm 2.13$ \\
\hline
\end{tabular}

fly size. Measurements were made from the front end of the insertion of the left wing to the most distal projection of that wing. Care was taken to measure the wing in the normal "resting" position in which the wing is folded back over the abdomen.

Size measurements were also made by photographs, especially when the capture of flies was likely to influence the outcome of the experiment. Photographs were taken from a position perpendicular to the long axis of each fly's body using a 100 $\mathrm{mm}$ macro-telephoto lens and $35 \mathrm{~mm}$ camera, set at the widest aperture setting ( $f=4.0$ ) and the longest focal length. Focusing the camera by moving it the proper distance from the fly allowed me to produce an image consistent with the fly's size. An ocular micrometer mounted on a dissecting microscope was used to measure fly images. Comparisons of flies measured by analysis and photographic technique show a strong correlation $\left(r^{2}=0.97\right.$, $N=26$ ), implying a high degree of accuracy for both methods of measurement. Wing length was strongly correlated with both $\log$ body length $\left(r^{2}=0.925\right)$, and $\log$ dry weight $\left(r^{2}=0.995\right)$.

For each treatment all amplexing flies were photographed during three successive sampling runs taken at 45-min intervals. All single males were counted on each of these runs and photographs were taken of a subset of these males. In most cases the fifth male counted was photographed. Photographs were later measured to determine male size.

Statistical tests used to analyze data include: $t$-test, $F$ test, and Simple Linear Regression (Steele and Torrie, 1960); Chisquare test and Kruskal-Wallis test (see Conover, 1971). An ANOVA was performed using the GLM program from the
SAS statistical package. R. Thisted of the Department of Statistics, the University of Chicago, suggested an appropriate transformation for data used in ANOVA. Means are shown as $\mathrm{X} \pm 0.95$ C.I.

Field studies were carried out in a pasture on the east side of Wagner Road, 300 $m$ south of its intersection with Scio Church Road, $5 \mathrm{kw}$ SW of Ann Arbor, Washtenaw County, Michigan. At the time studies were carried out, approximately 25 cows had been maintained in the pasture for several months and had eaten or trampled most of the tall grass. The cows spent the night in this pasture, but occupied an adjacent pasture to the southwest (Fig. 1) during the day.

The study site is a sloping "lawn" in the north pasture, where the grass was dense and cut short by grazing. Surrounding fields were planted with corn, clover and barley.

The farm on which these experiments were carried out is isolated from other pastures by $1.8 \mathrm{~km}$.

\section{RESUlTS \\ Male Distribution}

Predictions about the effect of resource structure on male mating success are largely dependent on how males are distributed over resources that are of value to females and can be controlled by males (Brown, 1963). Males may aggregate on resources because ovipositional resources are scarce, or because females prefer to mate with males in groups. Females may be attracted to grouped males because they offer more protection from predation (see Lack, 1954; Hamilton, 1971) or because dominance relationships among males allow discriminating females a reproductive advantage, e.g., better quality mates (good genes) or protection from other searching males. Alternatively, males may be dispersed if resources important for attracting or capturing females are scattered.

The effect of changes in resource availability and fly density on the number of males per pat is shown in Table 1 . The 

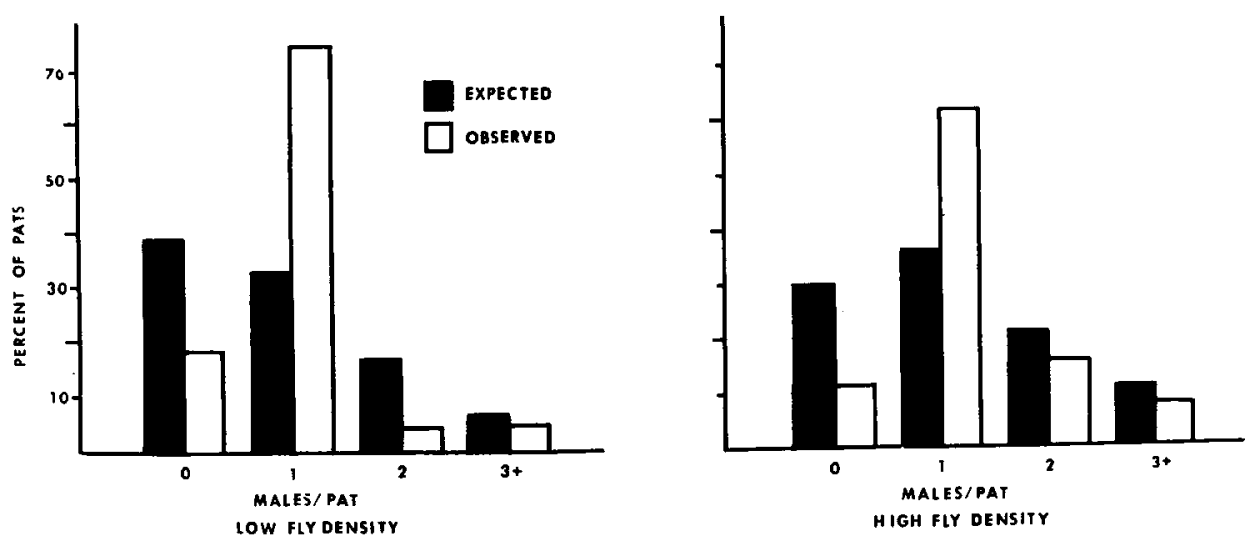

FIG. 2. The distribution of males over pats at high resource availability, for both (a) high, and (b) low male density $35 \mathrm{~min}$ after deposition. The percent of males observed and expected (Poisson) are shown. There are significant differences between expected and observed distributions (a) $\chi^{2}=729.23, P<.001$; (b) $\chi^{2}=141.77 ; P<.001$.

most noticeable effect is due to changes in resource availability, although similar but less dramatic effects were observed at high and low fly density.

Males appeared to spread evenly over the available pats. At both low and high male density, pats with one male per pat were by far the most common (Fig. 2), resulting in a uniform distribution of males. This implies that (1) resource distribution is critical in describing male distribution patterns, and (2) that there are no important epigamic or lek-like benefits associated with grouping.

\section{Male Size}

Data on male size were analyzed using a $2 \times 2 \times 2$ ANOVA with male population density, resource availability, and male status (along or amplexing with a female) as factors. The transformation $\ln (11$-size) was used to remove a strong negative correlation between cell means and cell variance. Results from the ANOVA analysis are shown in Table 3. All main effects were significant. The only significant interaction occurred between density and status.

Resource availability. -Table 4 shows probability values resulting from all pairwise comparisons of means among cells in which resource availability was the only factor allowed to vary $(1-3 ; 2-4 ; 5-7 ; 6-8$; Table 4). In each case the mean size of males was larger at low resource availability. Variance in the size of males was greater at high than at low resource availability for all four comparisons ( $F$ test; $P<.01$ ). Thus at low resource availability males of small size classes are especially rare on and around pats. Elsewhere I have shown that small males are scarce on these pats because of the damage they may suffer from encounters with large males, and because large males often take over any female they can capture (Borgia, 1980).

Population density.-Population density had its strongest effects on the size of unpaired males on pats. There were strong statistical differences in pairwise contrasts (1-5; 3-7; Table 4) under both conditions of resource availability $(P<.001)$. Population density had significant effects on the size of amplexed males only at high resource availability (contrast 4-8, Table $4)$, and in that case effects were marginal $(P<.043)$.

Because data on the two levels of male density were taken almost one month apart, it is possible that the size distribution of males changed during this period and could account for the observed differences between treatments. Difficulties in 
TABLE 2. Descriptive statistics for male size.*

\begin{tabular}{|c|c|c|c|c|c|}
\hline Cell & Variable & $N$ & Mean & Standard deviation & $\begin{array}{l}\text { Standard error } \\
\text { of mean }\end{array}$ \\
\hline \multirow[t]{3}{*}{1} & & & & den $=$ low $\quad$ res $=$ low & status $=$ unpaired \\
\hline & size & 132 & 8.907 & 0.646 & 0.056 \\
\hline & $\ln (11$-size) & 132 & 0.995 & 0.464 & 0.040 \\
\hline \multirow[t]{3}{*}{2} & & & & den $=$ low res $=$ low & status $=$ paired \\
\hline & size & 37 & 9.439 & 0.419 & 0.069 \\
\hline & $\ln (11-$ size $)$ & 37 & 0.587 & 0.415 & 0.068 \\
\hline \multirow[t]{3}{*}{3} & & & & den $=$ low $\quad$ res $=$ high & status $=$ unpaired \\
\hline & size & 68 & 8.263 & 0.837 & 0.101 \\
\hline & $\ln (11-$ size $)$ & 68 & 1.375 & 0.501 & 0.061 \\
\hline \multirow[t]{3}{*}{4} & & & & den $=$ low $\quad$ res $=$ high & status $=$ paired \\
\hline & size & 41 & 8.685 & 0.857 & 0.134 \\
\hline & $\ln (11-\operatorname{size})$ & 41 & 1.110 & 0.557 & 0.087 \\
\hline \multirow[t]{3}{*}{5} & & & & den $=$ high res $=$ low & status $=$ unpaired \\
\hline & size & 76 & 9.470 & 0.634 & 0.073 \\
\hline & $\ln (11-$ size $)$ & 76 & 0.566 & 0.560 & 0.064 \\
\hline \multirow[t]{3}{*}{6} & & & & den $=$ high $\quad$ res $=$ low & status $=$ paired \\
\hline & size & 58 & 9.514 & 0.402 & 0.053 \\
\hline & $\ln (11$-size $)$ & 58 & 0.513 & 0.428 & 0.056 \\
\hline \multirow[t]{3}{*}{7} & & & & den $=$ high res $=$ high & status $=$ unpaired \\
\hline & size & 285 & 8.673 & 0.811 & 0.048 \\
\hline & $\ln (11-$ size $)$ & 285 & 1.118 & 0.566 & 0.034 \\
\hline \multirow[t]{3}{*}{8} & & & & den $=$ high $\quad$ res $=$ high & status $=$ paired \\
\hline & size & 104 & 8.982 & 0.713 & 0.070 \\
\hline & $\ln (11-$ size $)$ & 104 & 0.916 & 0.596 & 0.059 \\
\hline
\end{tabular}

* Abbreviations: den $=$ density, res $=$ resource level.

accurately sampling the male population without harming males removed the opportunity to test directly for seasonal changes in male size. However, there is evidence that the enhanced success of large males at high male density was not due to the relative scarcity of small males. Appearance of large numbers of small males near the pat (within $5 \mathrm{~m}$ ) at high male density $(\bar{\chi}=8.07 \pm 0.58, N=32)$ when there was no comparable group of small males at low density indicates that small males were present but did not take up positions on pats. Moreover, experiments in which males on pats were captured and removed (carried out while males were at high density; see Borgia, 1980; Fig. 1), show that the numerous small males present will colonize the pat once large males are removed.
Status. - The mean size of paired males is larger than that of unpaired males in three $(1-2 ; 3-4 ; 7-8$; Table 4$)$ of four cases $(P<.01)$. In the remaining case, that of high male density and low resource availability, the mean size of males reaches its highest values for both amplexed and unpaired males. Thus, the absence of a significant difference is due to the scarcity of small males on the pat, and is not due to enhanced success of small males. The difficulty small males have in obtaining positions on crowded pats, especially at low resource availability and high male density, accounts for the statistically signifcant interaction between density and status. It appears that at low male population density, as large males are amplexed with females, small males are able to come onto the pat. However at high density the large 
TABLE 3. Analysis of variance of male size (transformed data).

\begin{tabular}{lrrrc}
\hline \hline \multicolumn{1}{c}{ Source } & $d . f$. & $\begin{array}{c}\text { Sum of } \\
\text { squares }\end{array}$ & \multicolumn{1}{c}{$\boldsymbol{F}$} & $\boldsymbol{P}$ \\
\hline Den & 1 & 7.843 & 27.62 & .0001 \\
Res & 1 & 29.282 & 103.10 & .0001 \\
Status & 1 & 7.449 & 26.23 & .0001 \\
Den res & 1 & 0.019 & 0.07 & .7958 \\
Den status & 1 & 1.441 & 5.08 & .0245 \\
Res status & 1 & 0.001 & 0.01 & .9391 \\
Den res status & 1 & 0.754 & 2.66 & .1036 \\
Error & 793 & 225.218 & & \\
\hline
\end{tabular}

number of large males excludes small males even after most of the larger males are paired.

\section{Distribution of Amplexed Pairs}

The above results show that even at high resource availability, amplexed males are significantly larger than unpaired males, at both high and low density. This could occur either if large males are able to control pats preferred by females, or if females choose larger males because of size-related dominance among males or active female preference for large males (see Borgia, 1981).

Evidence useful for evaluating each of these hypotheses comes from comparing the distribution of amplexing and non-amplexing males on pats. For this comparison I categorized pats with and without amplexing males according to the number of males on the pat. For pats without copulators only the number of unpaired males is used to class a pat. On those with one amplexing male the number of remaining
ASSOCIATION OF PAIRS WITH MULTIPLE MALES

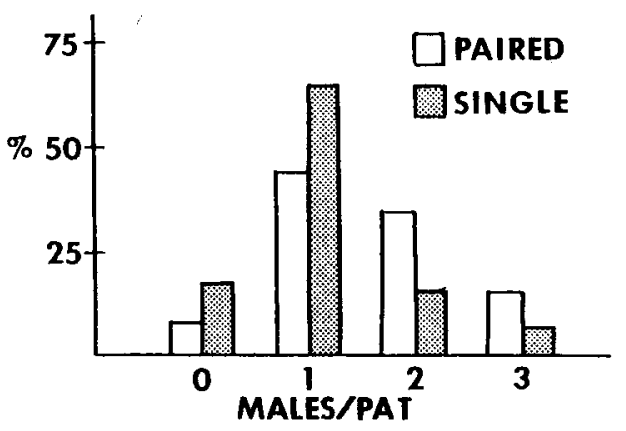

Frg. 3. Association of pairs with single males on pats. Pairs are classed according to the number of single males that share a pat with them. The observed percentage of paired males in each category (open) is shown with the expected distribution of pairs based on the frequency of pats of each type (stippled). Comparison of expected and observed distributions show a significant departure between these distributions $\left(\chi^{2}=30.96, P<.001\right)$.

males (both amplexing and non-amplexing) is used. These data show (Fig. 3) a greater than expected proportion of amplexing pairs on pats with two or more additional males. This result, although consistent with both of the above hypotheses, lends positive support to the first.

Parker $(1970 d)$ has suggested that females use wind-borne odor to find dung. Depending on how females search, this might affect their distribution over pats. I compared the numbers of copulators from four rows of pats ordered from windward to leeward. I was unable to detect any systematic bias among these rows

TABLE 4. Probability values from pairwise comparisons among cells (as defined in Table 2).

\begin{tabular}{|c|c|c|c|c|c|c|c|c|}
\hline \multirow{2}{*}{$\begin{array}{c}\text { Cell } \\
\text { number }\end{array}$} & \multicolumn{8}{|c|}{ Cell number } \\
\hline & $I$ & 2 & 3 & 4 & 5 & 6 & 7 & 8 \\
\hline 1 & & .000 & .0001 & .2279 & .0001 & .0001 & .0272 & .2269 \\
\hline 2 & & & .0001 & .0001 & .8413 & .5071 & .0001 & .0016 \\
\hline 3 & & & & .0119 & .0001 & .0001 & .0004 & .0001 \\
\hline 4 & & & & & .0001 & .0001 & .9178 & .0427 \\
\hline 5 & & & & & & .5684 & .0001 & .0001 \\
\hline 6 & & & & & & & .0001 & .0001 \\
\hline 7 & & & & & & & & .0007 \\
\hline 8 & & & & & & & & \\
\hline
\end{tabular}


$\left(\chi^{2}=3.86, d . f .=3, .2<P<.3\right)$. Female distribution on pats seems unaffected by wind direction.

\section{Discussion}

Male mate-searching behavior in $\mathrm{Sca}$ tophaga changes with the number of males in the population (Borgia, 1980). Under conditions where there are more than 10 males/pat, as occurred at low resource availability in the above-described experiments, males search over the entire pat surface with no apparent attempt to exclude other males. However, at lower numbers of males/pat, equivalent to high resource availability, males are extremely aggressive and may hold territories. When the results of the experiments reported above are considered in relation to male behavior, several important questions arise. One of these is if males are not territorial at low resource availability, then why are small males scarce around these pats? The apparent indefensibility (Brown, 1964) of these resources should allow equal access of all individuals to sites for capturing females. Results showing that the mean size of males is greatest at low resource availability suggest other reasons for the absence of small males. There is good evidence (Borgia, 1980, 1981) that small males may be avoiding interactions with large males who are searching for mates and the absence of small males is a by-product of searching behavior of large males. Direct physical harm may come from repeated encounters on pats in which small males may be especially susceptible to physical damage. In addition, small males typically gain less even if they are able to capture a female. Females are most often taken away from small males by other males than are taken from their larger counterparts (Borgia, 1980).

Another result that deserves attention is why copulators tend to be larger than other males under conditions of high resource availability. This result may be due to unevenness in quality among pats. Females moving into pats of high quality occupied by one male will most likely be captured by him and will copulate and oviposit under his control. If these males tend to be larger than average then the difference between the size of single and paired males can be accounted for. I attempted to make pats of identical size to exclude these effects, yet it is possible that position and substrate effects, along with some size variation, may have led to differences in pat quality which can be perceived by flies.

The high mating success of males at low effective densities may occur because: (a) males in groups are larger than the average for males on pats; (b) large males within groups are able to intimidate others of their group and therefore have better access to incoming females; or (c) females actively choose large males. There is no support for the hypothesis that unpaired males on or in the vicinity of pats, or in groups associated with pats at which there is a female, are larger than males alone on pats. No statistically significant difference exists in comparisons of lone males on pats with either of the groups of males mentioned above $(P>.1$ for both cases, see Table 4). There is, however, evidence to support each of the remaining alternatives. Observations on low male density pats (Borgia, 1980) show that males may establish territories from which they exclude other males from the upwind and central portions of the pat-the area where they are most likely to discover incoming females under these density conditions. Male size is directly related to success in establishing these territories. Females appear to actively choose large males, and to behave in ways on low density pats which cause them to be most often captured by dominant/large males (Borgia, 1981).

The strong effect of changes in patavailability on the size of copulating males together with the demonstration that females actively choose large males (Borgia, 1981) suggest a two-tiered decision pattern by females coming to pats to mate and oviposit. It appears that females are programmed to locate a suitable oviposition 
site. Then, to whatever degree possible, they choose among males present, favoring the largest. Such a choice by females may contribute to both the lowering of mean size of copulators in the presence of abundant, high quality oviposition sites and the observed difference in mean size of copulators and other males on pats.

\section{SUMMARY}

Experimental changes in the availability of oviposition sites (dung pats) used by the fly Scatophaga stercoraria were carried out in the field under varying conditions of male density. Both the distribution of resources and male density had significant effects on the distribution of males over pats of dung. Experimental changes also influenced the size-related success of males in gaining positions near pats where they could capture females, and the actual frequency with which these males captured females.

At high resource availability (many pats) and low fly density small males were relatively more successful in obtaining capture sites and females than at low resource availability and high fly density. Even so, large males had greater relative reproductive success than small males under all conditions. The size of paired males was larger than that of unpaired males who obtained positions on pats in all cases. This result occurred even where males were crowded on pats and large males seemed not to show any overt aggression toward smaller males on the pat. The relative absence of small males on these pats and their low success when present appear to be due to the high cost of encounters with large males searching for females (see Borgia, 1980, 1981). Success of large males at high resource availability appears to result from territorial behavior of large males in which they exclude smaller competitors.

Patterns of male success follow predictions from avian mating system models. However, these similar results occur because of the high cost to small males of searching for mates on pats with large males and not due to active exclusion by these males.

\section{ACKNOWLEDGMENTS}

This work was carried out as part of a doctoral dissertation at the University of Michigan. Particular thanks go to my doctoral committee Drs. Richard D. Alexander (Chairman), Robert Payne, Donald Tinkle and Aram Yengoyan. J. Miller Oppy, Dianne Burgin and Cliff Kiel were invaluable as field assistants. Larry Blumer, Diane de Forest, Diane de Steven, Marianne Fever, John Hoogland, Frank Hospod, Richard Howard, Cynthia Kagarise, Jan Lauridsen, Joan Miller, Katharine Noonan, Marlene Palmer, Paul Sherman and Randy Thornhill contributed to the production of this report. Support for field research was provided by the following groups: Theodore Roosevelt Memorial Fund, Sigma Xi, the National Science Foundation (BM575-17806), Rackham Graduate School-the University of Michigan, and Hinsdale and Walker funds at the University of Michigan. Preparation of this report was aided by a NIMH Grant (MH 15181) to Stuart Altmann.

\section{Literature Cited}

ALexANDER, R. D. 1975. Natural selection and specialized chorusing behavior in acoustical insects, p. 35-77. In D. Pimentel (ed.), Insects, Science and Society. Academic Press, N.Y.

Altmann, S., S. Wagner, and S. Lenington. 1977. Two models for the evolution of polygyny. Behav. Ecol. Sociobiol. 2:397-410.

Borgia, G. 1979. Sexual selection and the evolution of mating systems, p. 19-80. In M. Blum and A. Blum (eds.), Sexual Selection and Reproductive Behavior in Insects. Academic Press, N.Y.

-1980. Size- and density-related changes in male behaviour in the fly Scatophaga stercoraria. Behaviour 75:185-206.

. 1981. Strategies of mate selection in the fly Scatophaga stercoraria. Anim. Behav. 29:71-80.

BRADBURY, J., AND S. VEHRENCAMP. 1977. Social organization and foraging in emballonurid bats. III. Mating systems. Behav. Ecol. Sociobiol. 2:1-17.

BrowN, J. L. 1964. The evolution and diversity in avian territorial systems. Wilson Bull. 6:160169.

Conover, W. J. 1971. Practical Nonparametric Statistics. John Wiley, N.Y. 
Crook, J. H. 1964. The evolution of social organization and visual communication in weaver birds (Ploceinae). Behaviour Suppl.

1965. The adaptive significance of avian social organization. Symp. Zool. Soc. London 14:181-218.

EMLEN, S. T., AND L. W. ORING. 1977. Ecology, sexual selection, and the evolution of mating systems. Science 197:215-223.

Foster, W. 1967. Cooperation by male protection of ovipositing female in the Diptera. Nature 214:1035-1036.

Hamilton, W. D. 1971. Geometry for the selfish herd. J. Theoret. Biol. 31:295-311.

HAMMER, O. 1941. Biological and Ecological Investigations on Flies Associated with Pasturing Cattle and their Excrement. Bianco Lunos Bogtrykkeri, Copenhagen.

LACK, D. 1954. The Natural Regulation of Animal Numbers. Oxford Univ. Press, London.

ORIANS, G. 1969. On the evolution of mating systems in birds and mammals. Amer. Natur. 103:589-603.

PARker, G. A. 1970a. The reproductive behaviour and the nature of sexual selection in Scatophaga stercoraria L. (Diptera: Scatophagidae). I. Diurnal and seasonal changes in population density around the site of mating and oviposition. J. Anim. Ecol. 39:185-204.

. 1970b. The reproductive behaviour and the nature of sexual selection in Scatophaga stercoraria L. (Diptera: Scatophagidae). II. The fertilization rate and the spatial and temporal relationships of each sex around the site of mating and oviposition. J. Anim. Ecol. 39:205-228. 1970c. Sperm competition and its evolutionary effect on copula duration in the fly $S \mathrm{ca}$ tophaga stercoraria. J. Insect Physiol. 16:13011328.

- 1970d. The reproductive behaviour and the nature of sexual selection in Scatophaga stercoraria L. (Diptera: Scatophagidae). IV. Epigamic recognition and competition between males for the possession of females. Behaviour 37:113-139.

Payne, R., AND K. Payne. 1977. Social organization and mating success in local song populations of village indigo birds, Vidua chalybeata. Z. Tier. Psychol. 45:113-173.

PlesczYNSKA, W. 1978. Microgeographic prediction of polygyny in the lark bunting. Science 201:935-937.

Steele, R., ANd J. ToRrue. 1960. The Principles and Procedures of Statistics. McGraw-Hill, N.Y.

TrIvERS, R. 1972. Parental investment and sexual selection, p. 136-179. In B. Campbell (ed.), Sexual Selection and the Descent of Man 1871-1971. Aldine, Chicago.

VERNER, J. 1964. Evolution of polygamy in the long-billed marsh wren. Evolution 18:252-261.

Verner, J., AND M. WILlson. 1969. Mating systems, sexual dimorphisms, and the role of the male in North American passerine birds in the mating cycle. Ornithol. Monogr. 9:1-76.

WitTENBERger, J. F. 1979. The evolution of mating systems in birds and mammals, p. 271-349. In P. Marler and J. Vandenbergh (eds.), Handbook of Neurobiology. Plenum Press.

Corresponding Editor: D. J. Futuyma 